\title{
Conducting $\operatorname{poly}(N$-(1-Naphthyl) ethylene-diamine dihydrochloride) electropolymerization, characterization and electroanalytical applications
}

Waheed A. Badawy $\cdot$ Khaled M. Ismail •

Ziad M. Khalifa

Published online: 13 June 2007

(C) Springer Science+Business Media B.V. 2007

\section{Erratum to: J Appl Electrochem 37:593-604 DOI 10.1007/s10800-007-9290-8}

Unfortunately, there are two mistakes in the reference section of "Conducting poly( $N$-(1-Naphthyl) ethylenediamine dihydrochloride) electropolymerization, characterization and electroanalytical applications"' by Waheed A. Badawy, Khaled M. Ismail and Ziad M. Khalifa.
References 3 and 28 should be corrected as:

3. El-Abedin SZ, Borissenko N, Endres F (2005) Electrochem Comm 6:422

28. D’Eramo F, Marioli JM, Arevalo AA, Sereno LE (1999) Electroanalysis 11:481

The online version of the original article can be found under doi: 10.1007/s10800-007-9290-8

W. A. Badawy $(\bowtie) \cdot$ K. M. Ismail $\cdot$ Z. M. Khalifa

Chemistry Department, Faculty of Science, Cairo University,

Giza, Egypt

e-mail: wbadawy@wbadawy.csc.org.eg 